\title{
Lectoras y colaboradoras: voces femeninas en la prensa afroporteña en Buenos Aires a finales del siglo XIX
}

Readers and collaborators: Female Voices in the Afro-Porteño Press in Buenos Aires at the End of the 19th century

\section{Liz Moreno-Chuquen}

Idaho State University, Idaho, Estados Unidos

morelizQisu.edu

https://orcid.org/0000-0001-5445-4591

\section{Resumen}

Este artículo explora el rol de las mujeres afroporteñas como lectoras y colaboradoras en dos periódicos afroporteños, La perla (Buenos Aires, 18781879) y El unionista (Buenos Aires, 1877-1878). A partir del análisis de las secciones dedicadas a las noticias sobre las actividades sociales de la comunidad, la publicación de las cartas de los lectores, los pensamientos y las canciones de las sociedades carnavalescas, se examina la construcción de un discurso de corte afrofemenino desde una perspectiva feminista decolonial. El análisis señala que en las secciones secundarias las mujeres se representaron como lectoras y colaboradoras de la prensa afroporteña. Esto contrasta con la línea editorial de estos periódicos en la que se promovió una imagen de las mujeres circunscrita al espacio domésticoprivado. Estas publicaciones de las mujeres constituyen un discurso afrofemenino más plural, aunque no se trate de un discurso completamente autónomo de los marcos de dominación y marginalización con los que debieron convivir.

Palabras clave: prensa, afroporteñas, Buenos Aires, lectoras, discurso afrofemenino, 1877-1879.

\begin{abstract}
This study examines the role of Afroporteño women in two Afroporteño newspapers, namely $L a$ Perla (Buenos Aires, 1878-1879) and El Unionista (Buenos Aires, 1877-1878). By examining the beats devoted to news about the community's social activities, the publication of letters from readers, and the songs of carnival societies, this article analyzes the construction of an Afro-feminine discourse under a decolonial feminist perspective. The analysis indicates that women supported these journalistic projects as readers and contributors. Women's contributions to the press problematize the editorial frame under which the role of women was limited to the domestic-private space. These publications by women build up a more plural Afro-feminine discourse, although it is not entirely autonomous from the frameworks of domination and marginalization Afroporteño women had to coexist with.
\end{abstract}

Keywords: press, African descendant, Women of Buenos Aires, readers, Afro-feminine discourse, 1877-1879. 


\section{Introducción}

Desde mediados del siglo XIX la prensa alcanzó gran importancia tanto en Buenos Aires como en las demás provincias del país, pues,

se la ligaba al progreso, a la modernidad y a la civilización de los pueblos - pilares sobre los que se debía sustentar cualquier sociedad-y se la consideraba un motor de cambio social (...) la prensa era un elemento fundamental de una esfera pública (...) que mediaba entre la sociedad civil y el Estado (...) (y) sustentaba una opinión pública" (Geler, 2010, p. 27).

En este auge del periodismo escrito en Argentina surge lo que algunos historiadores, antropólogos y críticos literarios han denominado como la "prensa afroporteña" (Andrews, 1980; Lewis, 1996; Cirio, 2009; Geler, 2007, 2008, 2010, 2018; Yao, 2015)'. Se trata de un conjunto de periódicos dirigidos por intelectuales, músicos y escritores afroporteños durante las últimas décadas del siglo XIX. ${ }^{2}$ De este corpus se conservan la mayoría de los números publicados que corresponden a siete periódicos. Cada uno se publicaba con una frecuencia diferente, pero típicamente cada semana o diez días. Si bien este amplio corpus no se conserva en su totalidad, es posible encontrar una muestra significativa en la sala del Tesoro de la Biblioteca Nacional Mariano Moreno en Buenos Aires.

Entre los editorialistas y colaboradores se encuentran figuras afroporteñas sobresalientes como el payador y poeta Gabino Ezeiza y el poeta Casildo G. Thompson. Cabe destacar que los periódicos se caracterizaron por contar con un amplio grupo de colaboradores como Luis Ramírez, Froilán Bello, Juan Pablo Balparda, Rosario Iglesias, Felisa Pasos, entre otros miembros de la comunidad afroporteña ${ }^{3}$. De igual forma, los lectores, cuya participación es posible identificar en varias secciones que componen el corpus estudiado, incluidas las mujeres, también jugaron un rol importante pues se encargaron de sostener económicamente los periódicos, de organizar y liderar actividades sociales y culturales.

Este artículo examina las estrategias retóricas desarrolladas en la prensa afroporteña de finales del siglo XIX que visibilizan las prácticas sociales y culturales protagonizadas por las mujeres. Entre ellas se cuentan el liderazgo de tertulias, la suscripción a los periódicos, la comunicación con los editores y la publicación de sus propios textos. A través del análisis de las secciones dedicadas a eventos sociales y a la publicación de textos literarios se pretende complejizar la perspectiva que se ha mantenido sobre el rol de las mujeres en la prensa afroporteña. Por ejemplo, se ha argumentado que, a través de la prensa, se creó y circuló un discurso normativo y aleccionador sobre el rol de las mujeres, sobre todo en la esfera domésticoprivada (Geler, 2007; 2010). Si bien esto se puede comprobar cuando se realiza una lectura atenta de la línea editorial de la mayoría de los periódicos, una mirada a las secciones secundarias revela que las mujeres estuvieron involucradas en otras prácticas sociales que excedían lo que se esperaba de ellas en la esfera privada y/o doméstica. Como resultado, este estudio busca complejizar la perspectiva de los intelectuales afroporteños sobre su propia comunidad, en especial sobre las mujeres, su rol y participación en la construcción de la identidad nacional argentina.

Con el propósito de documentar quiénes eran algunos de los colaboradores, directores y fundadores de la prensa afroporteña, la obra Beneméritos de mi estirpe: esbozos sociales, de Jorje Miguel Ford, resulta de gran ayuda. De acuerdo con Eduardo Luis Duhalde, este es el único texto escrito en el siglo XIX por un afroargentino sobre un grupo de hombres afrodescendientes sobre los cuales no hay registros oficiales o han sido ignorados por las crónicas históricas (Ford, 2002, p.10). Todos ellos fueron miembros destacados de la comunidad afroporteña en la música, la poesía, la filantropía, el ejército y el periodismo (Ford, 2002) ${ }^{4}$. Entre el grupo de catorce afroargentinos reseñados por Ford se menciona a Froilán P. Bello y Casildo G. Thompson, colaboradores y redactores de El unionista (Buenos Aires, 1877-1878), La broma (Buenos Aires, 1876-1882) y La perla (Buenos Aires, 18781879). Aunque sus semblanzas se caracterizan por el uso de un tono laudatorio, Ford afirma que los dos nacieron en Buenos Aires, eran intelectuales, poetas y se dedicaron al periodismo ${ }^{5}$.

En el prólogo a la obra de Ford que se publicó en 1899, Augusto Marcó del Pont resalta la manera en que ésta puede servir de ejemplo para los "negros arjentinos" (sic) al resaltar la labor de aquellos miembros de su comunidad considerados ilus- 
tres en la esfera artística e intelectual (Ford, 2002 [1899], p.20). Por su parte Ford, se dirige a sus lectores y afirma que

nos alienta la esperanza de servir con nuestras modestas proyecciones intelectuales, a la perpetuación de la memoria de tanto hombre activo e intelijente (sic) que ha poseído nuestra raza en las riberas del Plata (...) animados por un jenuino (sic) sentimiento de veneración a los infatigables obreros, a los descendientes de la africana raza, a los que descollaron rompiendo la rutina a que estaban sujetos, no trepidamos en acercarnos a interrumpir la marásmica calma en que se columpia al soplo del indiferentismo la comunidad, con nuestra infecunda pluma que (...) adolecerá de muchísimos defectos" (...) (21-22).

Refiriéndose al perfil del grupo de afroporteños reseñados en su obra, entre los cuales no se incluye a ninguna mujer, Ford apunta a la proyección de un intelectual descendiente africano - hombreque se asemeja a un obrero que a través de su labor construye una identidad que no se asemeja a su predominante identificación como esclavo y cuyo imaginario aún persiste en el contexto en el cual escribe Ford. El uso de la palabra "obrero" le sirve para actualizar y, al mismo tiempo, vincular la agenda de los intelectuales afroporteños con un contexto global de afianzamiento del capitalismo.

En el caso específico de la Argentina, la obra de Ford y la prensa afroporteña resultan una excepción si se tiene en cuenta que el proyecto nacional en el cual se produjo un llamado a los inmigrantes europeos "a 'poblar' el país para así 'mejorarlo' les decir, blanquearlo/ europeizarlo)" en las últimas dos décadas del siglo XIX (Geler, 2018, p. 307). Estos inmigrantes se asentarían principalmente en Buenos Aires y se tomarían como "el eje principal de un mundo urbano popular de suma importancia en la construcción del imaginario del pueblo argentino blanco-europeo homogéneo" mientras se daba por terminado el proceso de desaparición de los descendientes de los esclavizados y esclavizadas de origen africano (Geler, 2018, p. 307). No obstante, una lectura de la prensa afroporteña permite una comprensión más amplia y crítica de lo que se ha considerado tradicionalmente como el mundo popular bonaerense.

A nivel temático, los periódicos contaban con una variedad de secciones permanentes como la edito- rial dedicada a discutir cuestiones raciales, sociales y de género -orientadas al rol de la mujer-. De otro lado, se encuentran secciones en las que se publicaban las cartas, poemas y aforismos - llamados pensamientos- de las lectoras y lectores, las noticias varias sobre las actividades sociales de la comunidad, variedades y, finalmente, avisos clasificados. Gran parte de la literatura afroargentina producida en esta época no se encuentra en libros, sino que se publicó en la prensa, específicamente en los periódicos mencionados anteriormente, a excepción de la obra de los poetas y payadores Ezeiza, Horacio Mendizábal, Luis García Morel e Higinio Cazón que se publicaron de forma independiente (Lewis, 1996, p. 4-5).

\section{Marco teórico}

En este estudio, la prensa se considera un espacio simbólico, retórico y de potencial identificación para la comunidad afroporteña desde el cual se generó un conjunto de discursos relacionados con la raza, el género y el progreso de los miembros de la comunidad, entre ellas las mujeres ${ }^{6}$. Los editores y colaboradores de estos proyectos periodísticos estaban alineados con lo que se denomina una "política de respetabilidad negra" de corte patriarcal. Este concepto utilizado por Frank Guridy y Juliet Hooker para explicar una de las etapas de la evolución del pensamiento afro-latinoamericano, a principios del siglo XX en Cuba, resulta productivo para analizar la prensa afroporteña. Esta política cultural abarca

la subordinación de la mujer, la plena integración de los afrodescendientes a la sociedad y la identidad nacional - lo cual implica la no reivindicación de una cultura afro separada del resto de la nación-y la adopción de normas culturales de corte europeo mientras se promueven espacios de discusión de las desigualdades sociopolíticas, incluido el racismo (Guridy \& Hooker, 2018, p. 219).

Esto significa que los afrodescendientes se han valido de diversas estrategias para insertarse en los proyectos de construcción de la identidad nacional y, a partir de allí, dar trámite a otro tipo de agenda relativa a la lucha contra el racismo y 
la desigualdad, aunque eso signifique limitar la agencia y visibilidad de las mujeres negras en la esfera pública.

La adopción del concepto de "política de respetabilidad negra" no pretende enfatizar el anquilosamiento de las ideas y reflexiones que se comunicaron a través de la prensa afroporteña, sino por el contrario, señalar que no fueron proyectos periodísticos monolíticos ${ }^{7}$. Siguiendo a Guridy y Hooker,

los intelectuales afrolatinoamericanos no tenían una postura única respecto a cuál era la mejor manera de movilizarse para oponerse a las desigualdades sociopolíticas que enfrentaban ellos mismos y el resto de las personas de ascendencia africana en las sociedades latinoamericanas $(2018$, p. 220)

De allí la dificultad de encasillar sus proyectos periodísticos que, tras una lectura atenta, se caracterizan por su fluidez discursiva y ambivalencia. En este sentido, es posible comprender la prensa afroporteña como un proyecto discursivo de largo aliento compuesto por voces y perspectivas alineadas hasta cierto punto, pero diversas en cuanto a su expresión.

En su conjunto, los editores y colaboradores de la prensa afroporteña se alineaban con lo que Dawson (2001) denomina proyectos de liberalismo negro. Los intelectuales afrodescendientes que se alinean con esta corriente de pensamiento si bien criticaban el racismo, defendían su integración a los estados nacionales en formación y a sus ideologías de inclusión social, y no incluían una perspectiva de género en sus propuestas políticas o intelectuales. En suma, se trataba de una labor de corte patriarcal a la cual las mujeres no tuvieron el mismo acceso ya que "los desafíos que debieron enfrentar las mujeres negras para acceder a los sitios tradicionales de producción intelectual fueron todavía mucho más grandes que en el caso de los hombres negros" (Guridy \& Hooker, 2018, p. 223). Si bien el carácter de política de respetabilidad negra y de liberalismo negro de la prensa afroporteña resistió el racismo y la invisibilidad negra, en todo caso se circunscribe a una matriz de colonialidad - relacionada con el patriarcado colonial/ moderno, el sexismo y la clase social- que hacen específica la exclusión y discriminación de género para las mujeres negras ${ }^{8}$.
Este estudio pretende visibilizar y analizar los mecanismos discursivos que produjeron un conjunto de voces femeninas en la prensa afroporteña, especialmente, en su rol como lectoras y colaboradoras de ésta. Lo femenino en tanto cuerpo sexuado $y$, en particular, las voces afrofemeninas son parte de un proceso de producción cultural que surgen en un contexto de subordinación racial y sexista (Espinosa \& Castelli, 2011). Estas voces polisémicas tienen el potencial de situar el pensamiento y la acción mientras señalan unas experiencias diferenciadas de carácter afrofemenino que los estudios sobre la prensa afroporteña aún se encuentran en proceso de estudiar y analizar. Esta perspectiva de análisis pretende posicionar a las mujeres afroporteñas como agentes de su propia experiencia teniendo en cuenta la complejidad de esa misma experiencia en un contexto postcolonial, heteropatriarcal y racista. Incluso es posible pensar que sus voces engloban estrategias de resistencia, aunque no se hayan dado de forma organizada ni sostenida a lo largo del tiempo.

\section{Metodología}

De acuerdo con Geler (2007), es posible identificar tres niveles discursivos sobre el rol de la mujer afroporteña en la prensa, específicamente en La broma y La juventud. En el primer nivel tiene lugar un discurso hegemónico de corte patriarcal sobre la mujer como "reproductora”, "ángel del hogar" y sujeto que debe "regenerarse" - educarse - para lograr el avance de la comunidad mientras la esfera doméstico/privada se entiende como su espacio de movilidad e influencia (Geler, 2007, pp. 116118). Una de las características más importantes de este nivel discursivo es que idealiza el rol que se espera de la mujer afroporteña en la sociedad y la familia. Ejemplos de este tipo de discurso se encuentran, sobre todo, en las editoriales de La broma y La juventud. ${ }^{9}$ En el segundo nivel se cuentan aquellos textos periodísticos en los que se evidenciaba una imagen más cotidiana de la mujer afroporteña. Por ejemplo, artículos en los que se reportaban discusiones entre ellas, se les pedía que se abstuvieran de concurrir a los paseos públicos o se destacaba la importancia de evitar la opulencia en el vestir (Geler, 2007, p. 119). En el tercer nivel, Geler ubica un discurso afrofemenino 
producido y/o protagonizado por las mujeres a través de las secciones dedicadas a los acontecimientos de la vida social afroporteña, las cartas de los lectores y la publicación de textos literarios.

Siguiendo la estructura planteada por Geler (2007) para el análisis de La broma y La juventud, este estudio sigue metodológicamente estos niveles discursivos para identificar y seleccionar los casos analizados, pero propone examinar con mayor profundidad el tercer nivel discursivo. Esto permitirá expandir el análisis sobre el rol de las mujeres como colaboradoras de la prensa, lectoras y miembros activos en la realización de eventos culturales y sociales reportados en otros periódicos como La perla y El unionista y, por extensión, en la sociedad afroporteña. Cabe aclarar que, en una variación de la metodología propuesta por Geler (2007), en este estudio se incluyen en el tercer nivel discursivo las noticias relativas a la intervención de las mujeres en actividades sociales y culturales, aun cuando éstas hayan sido reportadas por los editores y colaboradores, no directamente por ellas. De igual manera, en el análisis se privilegian aquellos textos que se construyen desde una(s) voz(ces) femenina(s) anónima(s) ya que tienen el potencial de proyectar un discurso plural y articulado emitido en un espacio público, masculino y subalterno como lo fue la prensa afroporteña.

El corpus objeto de este estudio se encuentra en la Sala del Tesoro de la Biblioteca Nacional Mariano Moreno, en Buenos Aires. Se consideraron treinta y tres números de La perla y siete de El unionista como las fuentes primarias de este estudio. La perla y El unionista circularon en Buenos Aires y Uruguay, y solo el segundo periódico circuló en la "campaña" - es decir, la provincia-. Para la elección de los casos que se analizan en la siguiente sección se revisaron los números publicados entre 1876 y 1879 de La perla y El unionista. Se prestó especial atención a las secciones "Pensamientos", "Hechos locales" y "Campo poético" para el caso del primer periódico; "Para-caídas" y "Noticias varias" para el caso del segundo.

\section{Análisis}

En La perla se reporta la existencia de una tertulia que llevaba el mismo nombre del periódico y "se pone en conocimiento de las señoritas que tienen lista de suscrición (sic) para la tertulia de 'La perla' que la reunión de la comisión tendrá lugar el Ocho del corriente, para entregar el dinero recoletado (sic). La tesorera" (1 de septiembre de 1878, nro. 24). Esta tertulia estaba conformada por las lectoras de La perla y su propósito era reunir fondos para sostener el periódico y/o la realización de las reuniones. El unionista también contaba con una tertulia de mujeres a la cual se le denominaba "fraganciosas flores del jardín de 'El Unionista" y conformada por al menos ocho mujeres 16 de enero de 1878, nro. 21). En general, en las tertulias se bailaba, se escuchaba música, se contribuía económicamente para el sostenimiento de los periódicos e, incluso, se trataban temas relacionados con lo que se publicaba en la prensa ${ }^{10}$.

Este tipo de tertulias conformadas por mujeres lectoras no fueron exclusivas de La perla, sino que también incluyeron otros periódicos afroporteños y la realización de actividades sociales encaminadas a garantizar la continuación de estos proyectos periodísticos. Al respecto cabe resaltar una breve nota en la sección "Noticias varias" de El unionista donde se lee que "el jueves pasado se dio otro baile á beneficio (sic) de 'La broma' en casa de la señora de Ezcurra, se que nos dice que estuvo muy concurrido" (9 de diciembre de 1877, nro. 17). Este tipo de notas también revelan que el apoyo de la comunidad para la realización de eventos sociales fue muy importante para el sostenimiento de los periódicos. Aunque la fiesta mencionada se realizó en la casa de Ezcurra, se requería de un buen número de asistentes para que el evento fuera un éxito como se reportó en la nota cuando se menciona que "se nos dice que estuvo muy concurrido".

El apoyo de las mujeres a los proyectos periodísticos de la comunidad no se dio de forma aislada, sino que hacían parte de una red de colaboración que se extendía a otros periódicos y que requería del apoyo de varias personas. La fiesta de la señora Ezcurra se publicó en El unionista, pero la reunión buscaba fondos para La broma ${ }^{11}$. Para el caso específico de El unionista, en uno de sus números se reporta que, de un total de dieciocho suscriptores, cuatro eran mujeres que pagaban $\$ 10$ pesos por la suscripción mensual al periódico. En cuanto a las actividades sociales, existía un número significativo de tertulias lideradas por mujeres. Entre los números consultados, se cuentan más de 
diez tertulias organizadas por mujeres a las que se invitaba a los redactores y colaboradores de los periódicos.

La construcción discursiva de una audiencia afrofemenina a la cual se dirigen notas, cartas y noticias fue clave para el posicionamiento de las mujeres como lectoras de la prensa afroporteña. En varias oportunidades en la sección "Para-caídas" de El unionista, los editores agradecen a sus "amadas lectoras": "leales amiguitas las de la correspondencia a Martinita Brown, Joaquinita Echavarría, Celestina Acosta, Anita Céspedes, Marta Ejalde, Cristina Ezeiza y otras tantas que se interesan por la suerte de nuestro amado 'Unionista'" (16 de diciembre de 1877, nro. 18). En la sección "Variedades" en una carta de un lector de Burzaco - provincia de Buenos Aires - en la cual se lee "mi querido director. Actualmente tiene el 'El unionista' gran circulación principalmente entre el bello sexo, á quien dedico las siguientes líneas..." (30 de diciembre de 1877, nro. 20). En el corpus analizado, se encuentra al menos un artículo por número en la sección de "Variedades" dirigida a las "bellas lectoras", "mis bellas lectoras", "amabilísimas lectoras" o "lectoras de 'El unionista'”.

Una de las estrategias utilizadas por los editores para resaltar la presencia de una audiencia afrofemenina consistió en construir su identidad como parte de un diálogo entre ellas, los redactores y los lectores. De hecho, en otros periódicos argentinos del mismo periodo se publicaban textos de corte amoroso, en su gran mayoría, escritos desde una perspectiva masculina y dirigidos al público lector femenino. Lo relevante en el caso de El unionista y La perla es que a la construcción de lo femenino se le agrega el componente racial que inserta a la mujer negra en la formación de una cultura y un discurso nacional de los cuales, predominantemente, se le excluye. La audiencia afrofemenina se construye como receptora activa de los discursos que circulaban en la prensa.

Ante la evocación y el reconocimiento de una lectora afrofemenina de la prensa afroporteña, cabría preguntarse por la inclusión de voces femeninas como colaboradoras en la prensa. En periódicos como La perla, las mujeres publicaron sus textos. En la sección "Pensamientos" de La perla se publicaron frecuentemente textos cortos en forma de reflexiones o pensamientos firmados por mujeres y hombres, algunos de corte poético. Se publicaban alrededor de diez reflexiones en cada número, con una participación mayoritaria de las mujeres. Florentina Cabrera escribe en la misma sección la siguiente reflexión: "Hay muchas cosas en la vida que pueden distraer la imaginación de la mujer, pero la lectura sobre todo; es lo más bello" 11 de septiembre de 1878, año 1, nro. 24). Florentina Cabrera expresa que: "Cuando encontraré una amiguita de mi agrado que me anime á los paseos y tertulias, y entonces me concretaré más feliz" 11 de septiembre de 1878, año 1, nro. 24). Cabrera relaciona el gesto de asistir a las tertulias con la felicidad que, en el contexto de otras publicaciones, se relaciona con el bien común. En esta voz femenina se expresa un deseo por circunscribirse a espacios sociales más allá de la esfera doméstico/privada en la cual se esperaba que la mujer permaneciera según la línea editorial de estas publicaciones. De igual manera, la mención de una "amiguita" comunica la idea de que para ingresar en estos ambientes sociales es deseable recibir el apoyo o la asociación con otras mujeres.

Petrona Suárez escribe en la misma sección el siguiente pensamiento: “ $¡$ Cuán divino es en la mujer hermosa, con un lunar quela (sic) la embellesca (sic) cual una matizada rosa" junto con otros escritores como Froilán P. Bello - reconocido intelectual afroporteño-, Manuel Garay y otras autoras como Mercedes Villegas, Isabel Villalva, Enriqueta Jaines, entre otras (15 de junio de 1879, año 2, nro. 50). Esta reflexión de Suárez sigue la estructura de un par de versos con rima consonante cuya temática no es amorosa, sino que se refieren al cuerpo femenino, más específicamente, a una de sus características, el lunar. Esta atención al lunar por parte de Suárez sugiere, de un lado, la fragmentación del cuerpo femenino y, de otro, paradójicamente, la construcción de una mirada divergente que va un poco más allá del deseo colonizado y de los imaginarios racistas y sexistas que reduce el cuerpo femenino al espectáculo mientras se hipersexualiza. Este pensamiento de Suárez se puede entender como parte de un proceso más amplio sobre la construcción del cuerpo femenino desde una perspectiva femenina. La mayoría de los pensamientos escritos por mujeres reflexionaban en torno al amor, el desamor, el pasado y la amistad ${ }^{12}$.

La participación de las mujeres en diversas actividades artísticas, culturales y literarias altamen- 
te significativas para la comunidad afroporteña, como el carnaval, se difundió a través de la prensa. Los periódicos consultados dedicaron varios de sus números y secciones a informar sobre diversas actividades relacionadas con el carnaval y las canciones que allí se interpretaban. Por ejemplo, La perla publicó un par de canciones interpretadas por las comparsas de Montevideo (Uruguay) como la de los "Negros Lubolos" (20 de marzo de 1879. nro. 44). El unionista en la sección "Noticias varias" anuncia que la sociedad "Estrella del Sud", "Cruzeros del Sud y los "Hijos de Guinea" convocan a reuniones y ensayos para recorrer las calles en el próximo carnaval (20 de enero de 1878, nro. 23). Otros periódicos que exceden el foco de este estudio también informaron sobre estas actividades. La juventud anuncia el inicio de ensayos de las comparsas y grupos musicales como la sociedad "Tenorios musicales" (22 y 23 de enero de 1876, nro. 4), y la importancia de su celebración: "La ciudad de Buenos Aires debe mostrarse espléndida para demostrar así que con la crisis que no ha pasado de ser siempre lo que era antiguamente" (La juventud, 6 de febrero de 1876, nro. 5). La perla decide publicar algunas piezas musicales compuestas por las sociedades carnavalescas y que se interpretaron durante el carnaval con el propósito de visibilizarlas y popularizarlas. Con respecto a las sociedades carnavalescas, Cirio afirma que

\footnotetext{
los afroporteños tenían un fuerte sentido gregario pues gran parte de sus actividades eran canalizadas a través de (...) 140 'sociedades carnavalescas' o simplemente 'comparsas', las que podían ser masculinas, femeninas o mixtas, distinguiéndose cada una por su vestimenta y repertorio, entre otras cuestiones (2015, p. 5).
}

Entre ellas, "62 de las cuales son mencionadas en los periódicos" (Frigerio \& Lamborghini, 2011, p.19). Para los propósitos de este estudio se analizarán algunos ejemplos que se refieren a la construcción de una autoría y voz femenina ${ }^{13}$. Entre ellas se resaltan las canciones de la sociedad "Las negras bonitas" que compusieron una pieza llamada "Tango": ${ }^{14}$

\footnotetext{
Las negras bonitas, hoy,

Venimos aquí á cantar,

Por medio de los deleites

Que nos brinda el carnaval VOCES

Son estos bellos días
}

\begin{abstract}
Para penas olvidar,
A pesar de los engaños

Con que quieren cautivar,

Disfrutemos compañeras

Los placeres de estos días

No perdamos un instante

De la danza á disfrutar
\end{abstract}

(La perla, 9 de marzo de 1879, nro. 43)

A través de este tipo de composiciones se revela un gesto de autoidentificación racial de las mujeres que, muy probablemente, posibilita el espacio del carnaval. Asimismo, se interpela a una audiencia que involucra a otras mujeres cuando expresa "Disfrutemos compañeras" (...) "No perdamos un instante". El uso del plural construye un público objetivo a quien se dirige un discurso emitido por un grupo de "negras bonitas", como se expresa al inicio. En la siguiente composición de "Las bromistas" también catalogada como tango, pero titulada Lenitivo contra la voz se expresa:

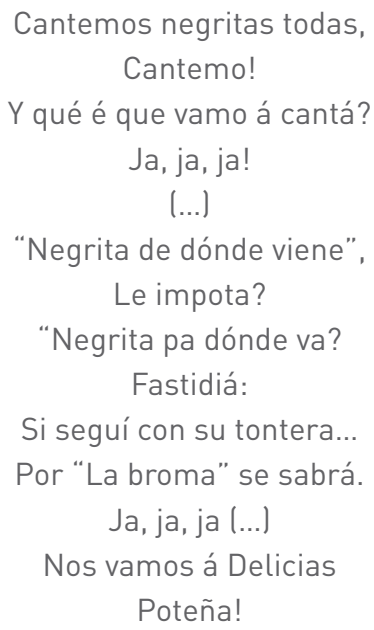

(La perla, 9 de marzo de 1879, nro. 43)

A diferencia de la composición anterior que sugiere un tono y registro más formal, en esta se observa el gesto de simular fonéticamente el habla popular afrodescendiente lo que confiere cierto tono festivo a la composición y una identificación -en términos identitarios- aún mayor que en Tango. De manera similar, el humor y la autonomía se revelan ahora como elementos importantes en la construcción identitaria afro femenina. En el fragmento citado, las mujeres voz principal del tango- interpelan una voz exterior - posiblemente masculina- que las inopor- 
tuna e interpela. Para esta subjetividad plural, la interpelación produce la posibilidad de acceder a un tipo de agencia gracias a la opción de producir y emitir un discurso que suspende imaginarios racistas y sexistas que reducen y afectan directamente la autonomía de las mujeres negras. El tono serio de los discursos sobre el deber ser de las mujeres que varios intelectuales afroporteños promulgaron a través de la línea editorial de los periódicos contrasta con este tipo de prácticas en la cuales las mujeres se expresan en un espacio menos restringido a través del humor, la emocionalidad, espontaneidad, la interpelación y el ejercicio de su agencia. Aunque la autoría del poema se adjudica a la sociedad de "Las bromistas" y se publica, a su vez, en un medio dirigido por hombres, la voz poética femenina se construye a través de un diálogo en el cual se configura una agencia y autonomía que responde a las preguntas que se plantean desde una subjetividad masculina.

La primera pregunta $-i Y$ qué é que vamo á cantá?- se presenta como una de tipo retórico que posibilita la incursión del humor - Ja, ja, ja!-y cierta libertad de elección en la respuesta que rectifica el liderazgo de la voz poética femenina en el diálogo. Algo similar sucede con la segunda y tercera pregunta que plantea de nuevo un intento de la voz que formula la pregunta - se podría pensar que simboliza lo masculino- de retomar la agencia y control del diálogo; sin embargo, las respuestas nuevamente devuelven la agencia a la autonomía a la voz poética afrofemenina. Recursos como el humor, la ironía y la interpelación posibilitan este diálogo en forma de composición musical e interpretado durante el carnaval. El comentario final sobre "La broma" se refiere al periódico que lleva este mismo título y al dicho popular entre la comunidad afroporteña de que "esto por La broma se sabrá", lo cual resalta la importancia de este periódico en la actualización de todo tipo de información relacionada con la comunidad y la expectativa que causaba entre la audiencia lectora, incluida la femenina. No hay evidencia que permita comprobar esto, pero probablemente el nombre de la asociación "Las bromistas" se debe a la cercanía de este grupo de mujeres con el periódico La broma, ya sea como lectoras, participantes de alguna tertulia o beneficiarias de algún tipo de ayuda económica que hacía posible la continuación de la asociación.

\section{Conclusiones}

De acuerdo con la mayoría de los estudiosos, la prensa afroporteña intentó “llevar a cabo desde ese espacio funciones disciplinadoras, educadoras, civilizadoras y regeneradoras de una comunidad que debía diferenciarse de un pasado de "barbarie" y de las "cosas de negros" (esto es, cosas inapropiadas según el común decir de la época)" (Frigerio \& Lamborghini, 2011, p. 20). En el caso específico del rol de las mujeres negras se intentó diseminar un discurso pedagógico-normativo que condujera, principalmente, a que se asumieran como "ángeles de sus hogares". Los intelectuales afroporteños consideraban que estos eran los mecanismos fundamentales para la regeneración y el acceso de la comunidad afroporteña en un proyecto nacional cimentado en el progreso, la civilización, el afianzamiento del capitalismo y el patriarcado como fuerza que legitimara la distribución desigual de los roles de género. En este contexto, los discursos de las mujeres afroporteñas que circularon en la prensa son un ejemplo representativo de cómo un grupo marginado intentó participar y hacerse un lugar en un contexto y bajo una serie de condiciones que se le oponían o limitaban su agencia.

Si bien es cierto que no es posible corroborar la identidad de las mujeres y la veracidad de las notas que les dirigen redactores y lectores, estas estrategias retóricas producen una imagen identitaria de la mujer afro porteña como una ciudadana activa que participaba de los proyectos intelectuales de su comunidad. Mientras el discurso normativo hacia la mujer afroporteña, en tanto cuerpo sexuado, se emitió, indudablemente, desde la línea editorial de los periódicos - en un primer nivel discursivo-, una lectura de las secciones dedicadas a informar sobre las actividades sociales resalta dinámicas de asociación y participación de las mujeres afroporteñas. Este tipo de notas relativiza ese discurso altamente normativo y sexista sobre la mujer negra en Buenos Aires. En ese sentido, las mujeres pasan de ser objeto de discusión entre los editores que imponen sobre ellas un discurso sexista a ser sujetos que actúan como lectoras y que, incluso, se comunican con los editores para incidir en el tipo de información que se publica.

Los textos examinados construyen una voz e identidad afrofemenina más diversa y fluida que la 
imagen idealizada que los intelectuales afroporteños promovían en sus periódicos dada su posición paradójica con respecto a la "política de respetabilidad negra". Tanto las mujeres como los hombres, especialmente los editores, que colaboraron con la prensa afroporteña tuvieron que negociar su lugar de enunciación dada la multiplicidad de variables que concurren en el ejercicio de expresarse públicamente a través de la prensa en un contexto de invisibilización de la presencia afrodescendiente en el país y de "política de respetabilidad negra". Si se piensa que la editorial ocupaba un espacio central, al examinar las secciones secundarias, como aquellas dedicadas a las actividades sociales, las cartas de los lectores, a los textos literarios lincluidas las reflexiones y las canciones carnavalescas) se revela que las mujeres afroporteñas se construyeron como seres sociales y visibles. La prensa posibilitó su vinculación como lectoras y colaboradoras. Ejemplos de lo anterior lo constituyen su labor en la prensa como organizadoras y asistentes a las tertulias, colaboradoras que veían sus textos publicados, incluidas las reflexiones y las canciones carnavalescas. Estas publicaciones constituyen un discurso afrofemenino más plural, aunque no se trata de un discurso completamente autónomo e independiente de la matriz de dominación que las mujeres afroporteñas enfrentaron y con el cual convivieron. De este modo, la prensa afroporteña se convierte en un espacio retórico que refleja la dificultad, tal vez la imposibilidad, de ejercer un control total sobre su propio discurso y su audiencia mientras se revela como una fuente imprescindible para la comprensión del mundo popular urbano afroporteño de finales del siglo XIX.

\section{Notas}

1. Aunque Andrews, Cirio y Geler coinciden en reconocer la existencia de la prensa afroporteña como corpus documental, su aproximación crítica a los mismos difiere. Andrews es uno de los primeros en reconocer la existencia de este corpus, pero su estudio se centra en la mención de El proletario y La raza africana (cuyos ejemplares no se encuentran en la Biblioteca Nacional ni en el Archivo General) (149-155). Cirio presenta en su obra Tinta negra en el gris de ayer: los afroporteños a través de sus periódicos entre 1873 y 1882 una selección de artículos de La igualdad, La broma, La juventud y El aspirante con el propósito de difundir y familiarizar a la audiencia con la prensa afroporteña. No obstante, su obra no incluye un análisis crítico de los mismos. Finalmente, Geler dedica su obra Andares negros, caminos negros a analizar un importante número de periódicos. Si bien este estudio se nutre de su extensa obra, busca enriquecer la discusión sobre la manera en que la prensa afroporteña abordó el rol de las mujeres en el progreso de la comunidad y en la construcción de la identidad nacional.

2. Estos periódicos son: La igualdad (1873-1874) fundado por Máximo Córvera y Pastor Gutiérrez; La juventud (1876-1879) fundado por Gabino Arrieta, Juan Pablo Balparda, Rómulo Centeno y Gabino Ezeiza; La broma (1876-1882) propiedad de Dionisio García; La luz (1878) dirigido por Juan Finghlay; La perla (1878-1879) dirigido por Luis Ramírez, Camilo Olivera y Guillermo Ramírez; El aspirante (1882) dirigido por Nicasio de Latorre y El unionista (18771878) entre cuyos colaboradores se cuenta Casildo G. Thompson y Froilán P. Bello.

3. El periodo comprendido entre 1882 y $1889-\mathrm{y}$ en el cual se publica la prensa afroporteña- resulta muy relevante dado que, a partir de 1887, se empuja la invisibilización de la población afrodescendiente en el país ya que fue la última vez que el censo nacional incluyó una pregunta sobre la pertenencia étnico-racial. A partir de entonces se verifica una doble invisibilización "histórica y estadística, explicada por causas como las guerras o la pandemia de fiebre amarilla, que se comulga con la exclusión de la narrativa de la nación" (Bidaseca, et. al, 2011).

4. Duhalde agrega que la obra de Ford se publicó originalmente en 1899 en la ciudad de La Plata. Además, se compone de una serie de "semblanzas sociales" desarrolladas a partir "del buen manejo de la información dispersa en los trabajos históricos y en la prensa de la época, complementados con la tradición oral aún viva entonces" (Ford, 2002, p. 10).

5. De hecho, Thompson es autor de Canto al África, un poema que se publicó por primera vez en La juventud el 10 de junio de 1878 y que Ford reproduce en la sección que le dedica a este poeta y periodista. Este poema ha sido ampliamente comentado por Andrews (1980, p.175) y Lewis (1996, p. 51-69).

6. Cabe mencionar que la discusión y el debate sobre el rol de la mujer en el avance de la nación no fue un asunto exclusivo de la prensa afroporteña. Desde principios del siglo XIX, a través de la prensa femenina, circularon ideas similares sobre la función de la mujer en la esfera privada; la importancia del matrimonio y la maternidad en la formación de futuros ciudadanos útiles a la nación y la necesidad de popularizar el acceso a la educación para las mujeres. Sin embargo, predominó la segregación espacial de la mujer al ámbito doméstico (Barrancos, 2007).

7. Yao en su estudio sobre la prensa afroporteña coincide en afirmar que la prensa afroporteña se alineaba con la "política de visibilidad" (2015, p. 145).

8. La política de respetabilidad negra y de liberalismo negro tienen lugar dentro de un contexto de colonialidad y "a pesar de que la colonialidad es una matriz que ordena jerárquicamente el mundo de 
forma estable, esa matriz tiene una historia interna: hay, por ejemplo, no solo una historia que instala la episteme de la colonialidad del poder y la raza como clasificador, sino también una historia de la raza dentro de esa episteme, y hay también una historia de las relaciones de género dentro mismo del cristal del patriarcado. Ambas responden a la expansión de los tentáculos del Estado modernizador en el interior de las naciones, entran con sus instituciones en una mano y con el mercado en la otra (...)" (Segato, 2011, p. 27).

9. Al respecto véase "Mujeres afroporteñas: un esfuerzo pedagógico" en Andares negros, caminos blancos. Argentina a fines del siglo XIX (2010).

10. Las tertulias organizadas por mujeres enfrentaron varios desafíos. Por ejemplo, los editores advierten que la realización de este tipo de eventos algunas veces se vieron amenazados por la reacción violenta de los hombres: "se zuzurra (sic) también que, ciertos jóvenes malcriados de cierto notable Club, piensan producir algunos escándalos como ser romper vidrios, simulacros de riñas, y otras guaranguerías" (El unionista, 16 de diciembre de 1877, nro. 18) [itálicas en el original].

11. La broma es uno de los periódicos más importantes dentro de la prensa afroporteña por su duración ya que se publicó durante seis años.

12. En cuanto al corpus literario que se publicó en la prensa afroporteña, la obra de Martin (1996) resulta fundamental para la comprensión de una "literatura menor" producida por los afroporteños a finales del siglo XIX y que circuló, principalmente, a través de la prensa. Su obra es un antecedente muy importante sobre el tema y se dedica a situar la producción literaria de los principales escritores (hombres) afroporteños como Mateo Elejalde, Horacio
Mendizábal, Casildo G. Thompson, Gabino Ezeiza, Lucas Fernández, entre otros, en el panorama de la literatura nacional. No obstante, el autor no aborda la escritura afrofemenina en su análisis.

13. Para una perspectiva más amplia sobre las canciones de las sociedades carnavalescas de la segunda mitad del siglo XIX véase el trabajo de Cirio (2015).

14. De acuerdo con Juan Carlos Cáceres (2010), el ímpetu de lo que él denomina una "posición negacionista" en relación con los orígenes afro del tango ha conducido a que aún en la actualidad se considere que "el tango de negro no tiene nada" (p. 13). No obstante, al explicar los orígenes del tango antes de la migración europea a la Argentina, Cáceres explica que en su génesis se encuentra el uso de los tambores de los candombes que acompañaban las comparsas de las Naciones desde finales del periodo colonial. “Más tarde, al bailarse el tango en pareja enlazada, los instrumentos europeos comenzaron a mezclarse con los de origen africano". (p.15) Finalmente, Cáceres establece que el tango trasciende gracias al sincretismo de su origen lafricano-europeo). Etimológicamente tango significa "tambor", pero al mismo tiempo "lugar de esclavos" o "sitios de esclavo" (p. 27).

\section{Publicaciones periódicas afroporteñas (Sala del Tesoro de la Biblioteca Nacional):}

\author{
La juventud 1876-1879 \\ La broma 1876-1882 \\ El unionista 1877-1878 \\ La perla 1878-1879
}

\section{Referencias}

Andrews, G. (1980). The Afro-Argentines of Buenos Aires, 1800-1900. Madison: University of Wisconsin Press.

Barrancos, D. (2007). Mujeres en la sociedad argentina. Una historia de cinco siglos. Buenos Aires: Editorial Sudamericana.

Bidaseca, K., Tesoriero, V., Puentes, J. P., Kaminker, S., González, M., Tabarosa, A., Greco, H., Mines, A., Saporito, C. \& Politti, l. (2011). (Reflexiones sobre la negritud femenina latinoamericana. Las voces de mujeres afrodescendientes en Ciudad de Buenos Aires). En Bidaseca, K. \& Vazquez, V. (compiladoras). Feminismos y poscolonialidad: Descolonizando el feminismo desde y en América Latina, (pp. 215-246). Buenos Aires: Ediciones Godot, Colección Crítica.

Cáceres. J.P. (2010). Tango negro: la historia negada, orígenes, desarrollo y actualidad del tango. Buenos Aires: Editorial Planeta.

Dawson, M. (2001). Black Visions: the Roots of Contemporary African-American Political Ideologies. Chicago: University of Chicago Press.

Cirio, P. (2009). Tinta negra en el gris del ayer: Los afroporteños a través de sus periódicos entre 1873 y 1882. Buenos Aires: Teseo Editores. 
Cirio, P. (2015). Estética de la (in)diferencia: las canciones de las sociedades carnavalescas afroporteñas de la segunda mitad del siglo XIX de cara al proyecto nacional eurocentrado. Latin American Music Review, 36 (2), 170-193.

Espinosa Y. \& Castelli, R. (2011). (Colonialidad y dependencia en los estudios de género y sexualidad en América Latina: el caso de Argentina, Brasil, Uruguay y Chile). K. Bidaseca, y V. Vazquez, (compiladoras). En Feminismos y poscolonialidad: descolonizando el feminismo desde y en América Latina, (pp. 191-212). Buenos Aires: Ediciones Godot, Colección Crítica.

Frigerio, A. \& Lamborghini, E. (2011). “Los afroargentinos: formas de comunalización, creación de identidades colectivas y resistencia cultural y política”. En R. Mercado y G. Catterberg, (compiladoras). Afrodescendientes y africanos en Argentina, (pp. 1-51). Buenos Aires: Programa de las Naciones Unidas para el Desarrollo (PNUD).

Ford, J.M. (2002). Beneméritos de mi estirpe: esbozos sociales. Buenos Aires: Catálogos.

Geler, L. (2005). Negros, pobres y argentinos. Identificaciones de raza, clase y de nacionalidad (1870-1880). Nuevo mundo. Mundos nuevos. https://journals.openedition.org/nuevomundo/449\#quotation

Geler, L. (2007). Nuestro sexo está de pie. Claroscuro, UNR, Rosario, 6, 109-137.

Geler, L. (2008). Guardianes del progreso. Los periódicos afroporteños entre 1873 y 1882. Anuario de estudios americanos, 65 (1),199-226.

Geler, L. (2010). Andares negros, caminos blancos: Afroporteños, estado y nación: Argentina a finales del siglo $X I X$. Rosario: Prohistoria Ediciones.

Geler, L. (2018). (Mujeres afrodescendientes en Buenos Aires a fines del siglo XIX: debilidad y castidad en entredicho). En Velázquez, M. E. \& González, C. (coordinadoras). Mujeres africanas y afrodescendientes: experiencias de esclavitud y libertad en América Latina y África, siglos XVI-XIX (pp. 307335). México D.F.: Secretaria de cultura, INAH (Instituto Nacional de Antropología e Historia).

Guridy, F. \& Hooker, J. (2018). “Corrientes de pensamiento sociopolítico afrolatinoamericano”. En De la Fuente, A. y Andrews, G.R. (Eds.). Estudios Afrolatinoamericanos: Una introducción, (pp. 219-267). Buenos Aires: CLACSO; Massachusetts: Afro Latin American Research Institute, Harvard University.

Lewis, M. (1996). Afro-Argentine Discourse: Another Dimension of the Black Diaspora. Columbia: University of Missouri Press.

Segato, R. (2011). (Género y colonialidad: en busca de claves de lectura y de un vocabulario estratégico descolonial). En Bidaseca, K. \& Vazquez, V. (Compiladoras). Feminismos y poscolonialidad: descolonizando el feminismo desde y en América Latina, (pp.17-47). Buenos Aires: Ediciones Godot, Colección crítica.

Yao, J.A. (2015). La prensa afroporteña y pensamiento afroporteño a finales del siglo XIX. Historia y comunicación social. 20 (1), (enero-junio), 137-147.

\section{- Sobre la autora:}

Liz Moreno Chuquen es Profesora asistente en el Departamento de lenguas y estudios globales en la Universidad Estatal de Idaho en Estados Unidos. Culminó su doctorado en literaturas y culturas latinoamericanas en la Universidad de Illinois en Urbana-Champaign. Desarrolló su tesis doctoral sobre la producción cultural de los afroporteños entre los siglos XIX y XXI, la cual recibió una mención de honor meritoria por parte de su facultad. Se especializa en estudios afro-latinoamericanos, particularmente en estudios visuales y literarios en Argentina y Colombia.

\section{- ¿Cómo citar?}

Moreno-Chuquen, L. (2021). Lectoras y colaboradoras: voces femeninas en la prensa afroporteña en Buenos Aires a finales del siglo XIX. Comunicación y Medios, (43), 104-114.

https://doi.org/10.5354/0719-1529.2021.58779 